\title{
Fiscal Policy and Optimal Taxation in Sierra Leone: Testing for Tax Smoothing Hypothesis
}

\author{
Samuel Bonzu ${ }^{1}$ \\ ${ }^{1}$ Macro-Fiscal Policy Division, Ministry of Finance, Sierra Leone \\ Correspondence: Dr. Samuel Bonzu, Director of Macro-Fiscal Policy Division at the Ministry Finance, Treasury \\ Building, George Street, Freetown, Sierra Leone.
}

Received: December 14, 2021

Accepted: December 29, $2021 \quad$ Online Published: January 7, 2022

doi:10.5539/ijef.v14n2p61

URL: https://doi.org/10.5539/ijef.v14n2p61

\section{Disclaimer}

The views expressed in paper are those of the author and do not necessarily reflect those of the Ministry of Finance.

\begin{abstract}
This paper empirically investigate whether the budget imbalances in Sierra Leone over the review period is consistent with optimal tax policy. The procedure involves testing if tax smoothing hypothesis hold for Sierra Leone. In this regard, three different empirical approaches were performed. Firstly, I examine the random walk property of the tax rate. The null hypothesis of non-stationarity of tax rate could not be rejected, which implies the tax rate follows random walk. Second, I examined whether changes in tax rate is predictable by regressing changes in tax rate by its own lagged values. The result shows that tax rate is unpredictable, as changes in tax cannot be determined by its lagged values. Finally, a VAR model was employed to examine whether tax rate can be predicted by its own lagged values together with changes in the government spending rate and the growth rate of real GDP. The results indicate that all the variables employed were found not be significant is predicating the tax rate. Overall, all the empirical estimations support the existence of tax smoothing over the sample period and that the budget inbalances over the review period is consistent with optimal tax policy.
\end{abstract}

Keywords: fiscal policy, tax smoothing, budget deficit, public debt

\section{Introduction}

Is the budget imbalances in Sierra Leone consistent with optimal tax policy? Following the 2008 global financial crises, many developed and developing countries experienced a deterioration in their budgetary positions. Sierra Leone, like many developing countries, has a long history of running budget deficits, and budget imbalances is a common phenomenon. The economy is experiencing rising public debt, persistent budget deficits and low revenue collections over the past decades. The high debt burden have to be financed at least in part by taxes and the effect of distortionary taxes on macroeconomy is well documented. Krumplyte (2008) have shown that excessive tax burden may cause an increase of a shadow economy that could lead to decrease of government revenue from taxes, especially in the case of lower economic development countries. Piketty, Saez, and Stantcheva (2014) argued that with distortionary taxes, top earners respond to taxes through three channels: labor supply, tax avoidance, and compensation bargaining.

With this in mind, I investigate how fiscal authorities have responded to the persistent budget inbalances over the years. However, to the best of my knowledge, no known studies have asked whether this situation is consistent with optimal tax policy. The purpose of this paper is therefore to empirically test whether the fiscal behaviour in Sierra Leone is consistent with optimal tax policy theory in the context of Barro's (1979) tax smoothing model.

The tax smoothing hypothesis formulated by Barro (1979) proposes that for tax policy to be optimal, the average tax rate should be smooth over time. The idea stems from the fact that tax collections are distortionary, and to minimise the welfare cost (excess burden) of taxation, collection should be spread over time. This optimal tax policy has the following implications: i) the issuance of public debt should respond positively to temporary increases in government spending and negatively to temporary increases in output; and ii) temporary changes in government spending and output should have no effect on tax rate. This last implication means that the tax rate should be unpredictable. 
Following Barro's (1979) foundational work, many studies have examined the existence of the tax smoothing hypothesis in both developed and developing counties or groups of countries. The empirical literature can be broadly categorised into two strands. The first strand examines the random walk behaviour and whether tax rate is unpredictable by its own lagged value or lagged values of other variables, as demonstrated in Barro (1981), Kingston (1984), Kingston and Layton (1986), Kingston (1991) and Strazicich (1996, 1997, 2002), among others. The second strand examines the relationship between budget balance and government expenditure. The idea here is that during bad times, the government is expected to run a deficit, either through an increase in spending or a cut in tax, and in good times, the government is expected run a surplus. According to this approach, tax smoothing should be counter-cyclical in nature. Studies that adopt this approach include Huang and Lin (1993), Olekalns (1997) and Cashin, Haque and Olekalns (1999) etc.

Using the methodology in Barro (1979), this paper contributes to the literature by providing recent empirical evidence of tax smoothing in Sierra Leone. Using annual time series data for Sierra Leone from 1980 to 2016, I adopt three different empirical approaches. First, I utilise a battery of unit root tests to examine the random walk property of the tax rate. The null hypothesis of non-stationarity of the tax rate cannot be rejected, which implies that the tax rate follows random walk, and hence is consistent with the tax smoothing hypothesis. Second, I examine whether changes in tax rate are predictable by its own lagged values by running a univariate regression. The result shows that tax rate is unpredictable, as changes in the rate cannot be determined by its lagged values. This finding also supports the existence of the tax smoothing hypothesis. Finally, a VAR model is employed to examine whether the tax rate can be predicted by its own lagged values together with changes in government spending rate and the growth rate of real GDP. The results indicate that all the variables employed are not significant in predicting the tax rate. Overall, the empirical estimation supports the existence of optimal tax policy in Sierra Leone over the sample period.

\section{Theorotical Framework and Literature Review}

The tax smoothing hypothesis formulated by Barro (1979) assumes that the present value borrowing constraints of the government, exogenously given non-interest government spending and the initial debt, determine the time path of government tax revenue. According to the Ricardian equivalence hypothesis, for a given amount of government spending, if taxes were lump sum, then the alteration to taxes and public debt to balance the budget would create no significant effect on the economy. However, in the absence of lump-sum taxation, approximation of non-lump-sum tax is as economically effective in the context of this hypothesis. Nevertheless, the absence of non-lump-sum taxes comes with the effect of excess burden, also known as the welfare cost of taxation.

This deadweight loss of taxation $(\mathrm{Z})$ is positively related to tax receipt $(\mathrm{T})$ and negatively to tax base $(\mathrm{Y})$. Barro (1981) specifies the welfare cost of taxation $\mathrm{Z}$ as follows:

$$
Z_{t}=F\left(T_{t}, Y_{t}\right)=T_{t} f\left(\tau_{t}\right)
$$

where $\boldsymbol{\tau}$ is the average tax rate $\left(\left(\frac{T_{t}}{Y_{t}}\right)\right.$.

According to Barro (1981), the government objective is to minimise the present value of the welfare cost of taxation Z:

$$
\sum_{t=1}^{\infty}(1+r)^{-1} f\left(\tau_{t}\right) T_{t}
$$

subject to the government present value borrowing constraint:

$$
\sum_{t=1}^{\infty}(1+r)^{-1} G_{0}^{t}+D_{0}=\sum_{t=1}^{\infty}(1+r)^{-1} f\left(\tau_{t}\right) T_{t}
$$

where $G_{0}$ is the non-interest government spending, $D_{0}$ is the initial public debt and $r$ is the real interest rate paid on public debt.

The constrained optimisation problem in equations (2) and (3) requires the government to choose a tax rate in each period, such that the present value of welfare cost of taxation is minimised with a given present value borrowing constraint. The necessary condition for the above optimisation problem requires that the marginal welfare loss of taxation be the same for all periods due to simultaneity in revenues from taxation and welfare loss. 
In other words, the planned tax rate should be constant over time. However, in the presence of uncertainty, the expectation of the current tax rate should be equal to the observed tax rate in the previous period, which means that the tax rate should follow martingale or random walk (Barro, 1981).

If the expected tax rate is constant, it implies that the level of taxes in each period is determined by $\mathrm{Y}$ and $G_{0}$ to maintain the present value borrowing constraint. However, if $\mathrm{Y}$ is constant over time, the constancy in $\boldsymbol{\tau}$ also means a constant $\mathrm{T}$. In the case where $G_{0}$ is constant, we have a balanced budget from the intertemporal budget constraint $T_{t}=G_{t}^{0}+r D_{0}$. In such a situation, however, the initial debt is not amortised. As such, the revenues from taxation are sufficient to meet interest payments on previous public debt and non-interest spending.

If $\mathrm{Y}$ and $G_{0}$ are growing at a constant rate, such that $Y_{t}=Y_{0}(1+\mu)$ and $G_{0}^{t}=G_{0}^{0}(1+\gamma)$, a constant $\boldsymbol{\tau}$ means that $\mathrm{T}$ is also growing at the same rate as Y. Given that $\boldsymbol{\mu}$ and $\boldsymbol{\gamma}$ are the conditional expectations of the growth rates of $Y$ and $G_{0}^{0}$, setting $\boldsymbol{Y}<\boldsymbol{\mu}<\mathrm{r}$, Barro (1981) derives the expected tax revenue at time zero as:

$$
T_{0}=\left(\frac{r-\mu}{1+\mu}\right)\left[\frac{G_{0}^{0}(1+\gamma)}{(r-\gamma)} D_{0}\right]
$$

Equation (4) implies that tax revenue is related positively to the growth rate of permanent non-interest spending and negatively related to the growth rate of permanent income.

In a situation where the time paths of $G^{0}$ and $\mathrm{Y}$ temporarily depart from their trend growth by irregular (+ or -) factors $v$ and $\zeta$ respectively, one period ahead $G^{0}$ and $\mathrm{Y}$ are given by

$G_{t}^{0}=(1+v) G_{0}^{0}(1+\gamma)$ and $Y_{t}=(1+\zeta) Y_{t}(1+\mu)$. Equating $\gamma=\mu$, implying that $\mathrm{T}$ and $G^{0}$ are growing at the same trend growth of $Y$ and assuming two period cases, Barro (1981) arrives at:

$$
T_{1}=\alpha\left[\left(G_{0}^{0}(1+\mu)+(r-\mu) D_{0}+v G_{0}^{0}(1+\mu) \beta+\right]\right.
$$

where

$$
\begin{gathered}
\alpha=\left[\frac{(1+\zeta)}{(1+\zeta)-\zeta((1+\mu) /(1+r))^{n}}\right] \\
\beta=1-[(1+\mu) /(1+r)]^{k}
\end{gathered}
$$

In Equation (5), $\left(G_{0}^{0}(1+\mu)\right.$ represents the permanent component of non-interest government spending, $(r-\mu) D_{0}$ is the interest payment net of output growth, $v G_{0}^{0}(1+\mu)$ is the temporary non-interest government spending, $\alpha$ is the factor that accounts for the influence of transitory income, $\mathrm{n}$ gives the duration of transitory departure of $\mathrm{Y}$ and $\mathrm{k}$ represents the duration of the transitory departure of $G^{0}$. The following implications emerge from equation (5):

(i) There are no effects of purely transitory expenditure on current taxation (if $\mathrm{k} \rightarrow 0, \beta=0$ ). If actual government spending deviates from its trend for a long period (if $\mathrm{k} \rightarrow \infty, \beta=1$ when $\mu<\mathrm{r}$ ), it implies the transitory expenditure has a positive impact on current taxation.

(ii) If changes in income are purely transitory (if $n \rightarrow 0$ ), their effect on taxes is specified as $\alpha=(1+\zeta)$. If the transitory deviation has a long-lasting effect, (if $n \rightarrow \infty$ ), $\alpha$ approaches infinity. Current taxes are therefore a decreasing function of the anticipated duration of transitory income.

According to Barro (1981), one way to test the above theoretical implications is to examine the constancy in the planned tax rate over time. The tax rate should be unpredictable, as it reflects only new information about the time path of government spending, output and other variables. This observation has led to the random walk tests on tax rate to investigate the tax smoothing hypothesis. Barro (1981) examines whether the United States government was carrying out an optimal tax policy by smoothing the distortionary effects of taxes. Barro (1981) uses average tax rate (tax revenue to GNP) as a proxy for marginal tax rate and finds that the tax rate follows a random walk. Additionally, he finds no predictive power for tax-rate changes from changes in government expenditure and growth of real output. As such, changes in tax rates are unpredictable upon arrival of new information. His findings are consistent with optimal tax smoothing hence an optimal tax policy.

Kingston (1984) tests for tax smoothing hypothesis in the United States using actual marginal tax rate from 1913 to 1975. His empirical results support the hypothesis of a random walk in tax collection costs, and the parallel hypothesis of tax rate is rejected. Trehan and Walsh (1990) adopt a similar approach and test for evidence of tax smoothing in United States using annual data from 1890 to 1982. Their results provide evidence of tax smoothing. Strazicich (1997) examines tax smoothing behaviour by the sub-national governments of Canada and the United States. He found that the tax smoothing hypothesis is rejected for state governments, but cannot be 
rejected for provincial governments. Horrigan (1986) uses annual United States data spanning from 1953 to 1978 and found that the tax smoothing hypothesis is rejected.

Sahasakul (1986) uses the random walk hypothesis of tax rate $\boldsymbol{\tau}$ to arrive at a relationship between the optimal tax rate and the permanent component of the government expenditure rate. Sahasakul (1986) expresses the government budget constraint as:

$$
D_{t}=\left(1+r_{t}\right) D_{t-1}+G_{t}^{0}-T_{t}
$$

Dividing throughout by $Y_{t}$, Sahasakul (1986) arrives at:

$$
d_{t}=\left(1+r_{t}-\mu_{t}^{\prime}\right) d_{t-1}+g_{t}^{0}-\tau_{t}
$$

where $d_{t}=D_{t} / Y_{t}$ is the debt income ratio, $g_{t}^{0}=G_{t}^{0} / Y_{t}$ and $\mu_{t}^{\prime}$ is the growth rate of output. Using the assumption of martingale together with the assumption of constant $r$ and $\boldsymbol{\mu}$, Sahasakul arrives at the following equation for optimal tax rat $\boldsymbol{\tau}$ at time t:

$$
\tau_{t}=\left(r_{t}-\mu_{t}^{\prime}\right) d_{t-1}+\left[\left(r_{t}-\mu_{t}^{\prime}\right) /\left(1+r_{t}-\mu_{t}^{\prime}\right)\right] \sum_{i=0}^{\infty} E_{t}\left(1+r_{t}-\mu_{t}^{\prime}\right)^{-1} g_{t+i}^{0}
$$

Sahasakul (1986) defines the first term on the right-hand-side from Equation (8) as the interest payment on public debt net of output growth, and the second part as the future expectation or the permanent component of government expenditure. Sahasakul (1986) uses annual United States data to test for the tax smoothing hypothesis by regressing marginal tax rate $\tau_{t}$ on the permanent expenditure rate. In contrast to Barro (1981), he found a significant tax rate response to changes in the permanent expenditure rate, which implies that tax rate is predictable, and that tax smoothing is rejected. In a similar vein, Jayawickrama and Abeysinghe (2013) test for tax smoothing behaviour by regressing the tax rate on the permanent expenditure rate. They argue that for tax smoothing to hold, future tax rates should cointegrate with the permanent expenditure rate even when the tax rate and expenditure rate follow random walk. Jayawickrama and Abeysinghe (2013) propose the concept of weak and strong evidence of the tax smoothing hypothesis depending on the degree of cointegration between the tax rate and the permanent expenditure rate. Using annual data spanning from 1954 to 2004 for Australia, Canada, Italy, Holland, the United Kingdom and the United States, they found evidence that tax smoothing holds for all these countries.

Some studies have concentrated on alternative features of the tax smoothing hypothesis. Instead of testing for evidence of random walk in the tax rate, some studies have tested for tax smoothing behaviour by investigating whether the budget balance (deficits/surplus) is informative about future changes in government spending. The government sets the budget balance for any period, equal to the presented discounted value of expected changes in government expenditure. The implication is that when expenditure is expected to rise, the government should run a surplus. Conversely, when expenditure is expected to fall, the government should borrow and run a deficit budget. Huang and Lin (1993), Ghosh (1995) and Olekalns (1997), among others, adopt Campbell's (1987) and Campbell and Shiller's (1987) VAR approach to explore and test all time-series implications of the tax smoothing hypothesis.

These authors start with one period, in which the government budget constraint is specified as:

$$
D_{t+1}=(1+r) D_{t}+G_{t}+\tau_{t} Y_{t}
$$

where $D_{t}$ is the stock of real government debt, $G_{t}$ is real government expenditure, $\tau_{t}$ is the average tax rate, $Y_{t}$ is real output and $\mathrm{r}$ is the fixed real interest rate.

If output grows at a fixed rate equal $\mathrm{n}$, equation (9) can be expressed as:

$$
(1+n) d_{t+1}=(1+\mathrm{r}) d_{t}+g_{t}+\tau_{t}
$$

with the lowercase letters denoting the ratio of the respective variable t output. Since equation (10) holds for every period, solving for $\tau_{t}$ by recursive forward substitution gives the standard intertemporal budget constraint in expected terms:

$$
\sum_{j=t}^{\infty}\left(\frac{1}{1+R}\right)^{j-t} E_{t} \tau_{j}=\sum_{j=t}^{\infty}\left(\frac{1}{1+R}\right)^{j-t} E_{t} g_{j}+(1+\mathrm{r}) d_{t}+\lim _{j \rightarrow \infty}\left(\frac{1}{1+R}\right)^{j} E_{t}(1+\mathrm{n}) d_{t+j}
$$

If the transversality condition on debt is imposed, i.e. the government cannot ignore a debt which has a positive expected present value: 


$$
\lim _{\mathrm{j} \rightarrow \infty}\left(\frac{1}{1+R}\right)^{j} E_{t}(1+\mathrm{n}) d_{t+j}
$$

gives

$$
\sum_{j=t}^{\infty}\left(\frac{1}{1+R}\right)^{j-t} E_{t} \tau_{j}=\sum_{j=t}^{\infty}\left(\frac{1}{1+R}\right)^{j-t} E_{t} g_{j}+(1+\mathrm{r}) d_{t}
$$

where $j$ is the index variable for time, $R=(r-n) /(1+n)$ is the effective net interest rate faced by the government, and $E_{t}=\mathrm{E}\left(\cdot I_{t}\right)$ is the expectation operator, conditional on the government's information set at time $t, I_{t}$. Equation (13) implies that the net present value of expected tax rate must be equal to the sum of the net presented value of expected government expenditure plus the initial debt.

When the government levies taxes, it is assumed that distortionary cost is imposed, such as collection cost and deadweight loss, which are incurred when individuals substitute market work. The government's aim is to minimise the welfare losses that occur due to the choice of the tax rate. These costs are assumed to be proportional to the square root of the tax rate. Following Barro (1979) and Ghosh (1995), the government's objective function is to maximise:

$$
V=-\left(\frac{1}{2}\right) \sum_{j=t}^{\infty} \beta^{j-t} E_{t} \tau_{j}^{2}, \quad 0<\beta<
$$

where $\beta$ is the government's subjective discount rate. The objective here is to maximise equation (14) subject to equations (10) and (12). Assuming $\beta=1 /(1+\mathrm{R})$, the Euler equation implies that for any $j>t$ :

$$
E_{t} \tau_{t}=\tau_{t}
$$

Equation (15) implies that the tax rate follows a random walk. This is the first basic implication of the tax smoothing hypothesis, which has been tested in several empirical studies, such as Barro (1981) and Sahasakul (1986). Substituting equation (15) into (12), the tax smoothing hypothesis can be written as:

$$
\tau_{t}=(r-n) d_{t}+\frac{R}{1+R} \sum_{j=t}^{\infty}\left(\frac{1}{1+R}\right)^{j-t} E_{t} g_{j}
$$

Equation (16) means optimal fiscal policy implies that the tax rate should constantly be set equal to the annuity value of the sum of government debt and the present discounted value of expected government expenditure.

Thus, the right-hand side of equation (16) is the constant flow of government expenditure that is anticipated to be sustained for the rest of the government's time horizon - that is, it is the permanent government expenditure. Optimal fiscal policy would mean that the tax rate should always be set to equal the permanent government expenditure.

If we define budget balance as:

$$
\mathrm{bal}_{t}=(1+n)\left(d_{t}-d_{t-1}\right)
$$

the dynamic government budget constraint can be written as:

$$
\mathrm{bal}_{t}=\tau_{t}-\left(g_{t}+(r-n) d_{t}\right)=\tau_{t}+g_{t}^{T O T}
$$

where $g_{t}^{T O T}$ is the total government expenditure, i.e. the sum of current expenditure $g_{t}$, and the effective interest payment on government debt $(r-n) d_{t}$.

After substituting equation (16) into (18), the tax smoothing hypothesis can be restated as:

$$
b_{t}=\sum_{j=t+1}^{\infty}\left(\frac{1}{1+R}\right)^{j-t} E_{t} \Delta g_{t}^{T O T}
$$

Equation (19) implies that for the tax smoothing hypothesis to hold, optimal fiscal policy requires that the budget balance for any period always be set equal to the presented discounted value of expected changes in government expenditure.

Thus, a temporary positive shock to expenditure means a deficit budget, whereas a permanent shock to expenditure means no change in the budget balance, as the tax rate is fully adjusted to the permanent shock. The 
behaviour of a tax smoothing government facing an exogenous expenditure is equivalent to the actions of a consumer who desires to smooth consumption over time when labour income is stochastic (Hall, 1978).

Huang and Lin (1993) test for optimal tax policy in the United States between 1929 and 1988. They found no evidence of tax smoothing behaviour. In accounting for structural breaks, evidence of tax smoothing is not rejected for after 1947. Ghosh (1995) tests for tax smoothing in the United States and Canada in the context of VAR. Using annual data from 1961 to 1988 , he found that the tax smoothing model is successful in explaining the behaviour of the federal government deficits for both countries. Olekalns (1997) found the Australian budget surplus to be too volatile to be fully consistent with optimal tax behaviour during the sample period of 1964-1995.

Crosby and Olekalns (1998) test for tax smoothing behaviour in Australia, the United Kingdom and the United States, and found that tax smoothing behaviour exists only for the United States. Serletis and Schorn (1999) test for tax and revenue smoothing for the United States, United Kingdom, Canada and France. They employ a tri-variate VAR and their results shows that tax and inflation smoothing hold, but revenue smoothing is rejected.

Some studies have concentrated on optimal tax policy from different perspectives. For example, the influence of optimal tax burden on economic activity and production capacity Abuselidze, (2012). The author shows that the tax burden impacts production technologies, efficient usage of resources and production capacity. However, the change in the tax burden influences government tax revenue that could be used to stimulate economic activity. Sinevičienè (2016) assesses a link between the tax burden and economic development for European countries using annual data from 2003 to 2012. The results shows that there are large disparities in the tax burden in the European Union countries. The tax burden on capital and consumption is greater in the very high economic development countries; but implicit tax rate on capital is higher in the case of countries with lower GDP growth, high government sector and high government debt. However, the tax burden on labour has declined, and the tax burden on consumption has increased or remained in the similar level in most countries.

The literature on developing countries is relatively thin compared to that on developed counties. Only a few studies have investigated the tax smoothing hypothesis in developing countries. For example, Cashin, Olekalns, and Sahay (1998) apply Barro's tax smoothing model to Indian data spanning from 1951 to 1997. They found evidence of tax smoothing behaviour in the central government, but show that the tax behaviour of state governments is inconsistent with the tax smoothing hypothesis.

Cashin, Haque, and Olekalns (1999) test for tax smoothing in Pakistan and Sri Lanka from 1956 to 1997. They found that the tax smoothing hypothesis holds for Pakistan but does not hold for Sri Lanka. As such, Pakistan's deficit behaviour is consistent with the tax smoothing hypothesis, while Sri Lanka's deficit behaviour is inconsistent with the hypothesis. Cashin, Haque, and Olekalns (2003) then test for optimal taxation in Pakistan for the period 1956-1995. Their results suggest that Pakistan's fiscal policy is optimal and consistent with tax smoothing behaviour, but the stock of public liabilities is on an unsustainable trajectory. Rocha (2001) investigates whether Brazil smoothed tax for the period 1970-1994. The results contradict the tax smoothing hypothesis. Rocha (2001) suggests that the performance of public debt may be explained from the standpoint of political economy rather than the idea of tax smoothing.

Using Chilean data spanning from 1972 to 2003, Pasten and Cover (2011) found strong evidence for the tax smoothing hypothesis when royalties from the copper industry are not under government regulation. On the other hand, weak evidence of tax smoothing hypothesis exists when royalties from the copper industry are regulated by the government. Kurniawan (2011) uses Indonesian data spanning from 1970 to 2010. He tests for tax smoothing behaviour in the context of Barro's (1981) model and finds evidence of optimal fiscal policy, which means that Indonesian fiscal policy is consistent with the tax smoothing hypothesis. Ashworth and Evans (1998) examine the existence of seigniorage and tax smoothing in a sample of 32 developing countries. They found that tax smoothing has not been a significant element in determining the behaviour of seigniorage. Talvi and Vegh (2005) examine the fiscal behaviour of 56 countries using annual data spanning from 1970 to 1994. They found that the fiscal policies in the G-7 follow tax smoothing behaviour, while developing countries are highly pro-cyclical. Belguith, Gabsi, and Mtibaa (2018) examined whether tax smoothing hypothesis holds for Tunisia, during the period 1972- 2015 using a direct testing method recently developed. Their results show the existence of the weak form of tax smoothing. The results also show that the observed random walk behavior of the tax rate does not guarantee the existence of the hypothesis application.

\section{Data}

Data on tax revenue is sourced from the World Development Indicator database and the National Revenue Authority, Sierra Leone. Total government spending is the sum of government consumption expenditure and 
government investment spending. and it is sourced from the World Development Indicators of the World Bank together with growth rate of real GDP. Tax rate and government spending rate are ratios which are arrived at dividing tax revenue and government spending by GDP. All variables are converted to real from their nominal values using the GDP deflator.

\section{Methodology}

The methodology employed in this study to examine whether the tax smoothing hypothesis holds for Sierra Leone is Barro's (1979) tax smoothing approach. The first empirical procedure tests whether tax rate follows a random walk, as this is the necessary condition for tax smoothing. Second, I examine whether tax rate changes are unpredictable, i.e. if changes in the tax rate can be predicted by its own lagged values or the lagged values of other variables. This approach is better suited to test for the tax smoothing hypothesis in developing countries like Sierra Leone for two main reasons. First, unlike the methodology in Ghosh (1995) and others that requires knowing the interest rate on total government debt, which is not fully available for Sierra Leone, this approach utilises the total government spending, total revenue and output growth rate, for which data is available. Second, the empirical procedure that is used in construction of the interest rate on government borrowing in Olekalns (1997) as well as other studies may not give the true value of the interest rate on total government debt, which is likely to affect the empirical results.

To carry out the empirical analyses on tax smoothing theory, I test for both random walk in the tax rate and the predictability of changes in the tax rate. To examine the random walk implication of tax smoothing, I employ a battery of tests to determine the tax rate $\tau_{t}$. If the null hypothesis of random walk is rejected, then tax smoothing will be rejected.

Second, I adapt a univariate autoregression to test whether changes in tax rate can be predicted by its own lagged values. Tax smoothing theory suggest that changes in tax rate should be unpredictable by its past value. This hypothesis is tested by regressing tax rate by its own lagged value. If the coefficients of the lagged values of tax rate are significant, it implies that the changes in tax rate are predictable, which implies tax smoothing theory is not observed.

Finally, I will employ a tri-variate VAR model to examine if changes in the tax rate can be predicted by changes in the government spending rate and the growth rate of real GDP. Tax smoothing theory suggests that changes in tax rate should be unpredictable even upon the arrival of new information. This means that tax rates should be unpredictable by their own lagged values, lagged values of government spending, and lagged values of growth rate of GDP.

There is a system of equations to test whether lagged values of a particular variable, together with lagged values of other variables, are better determined in the context of a VAR framework. The empirical literature has tested this hypothesis differently. While earlier studies such as Barro (1981), Sahasakul (1986), Horrigan (1986), etc., employ OLS, more recent studies, including Olekalns (1997), Kurniawan (2011) and Karakas, Taner and Yanikkaya (2014), etc., have tested this hypothesis in the context of VAR. I adopt the VAR framework to examine the tax smoothing theory in Sierra Leone, as it is better suited to such an analysis.

I will test for tax smoothing theory by first examining the random walk behaviour of tax rate. A battery of unit root tests- Augmented Dickey-Fuller (ADF) and The Phillip and Perron (PP) will be employed and are summarised as follows:

\subsection{The Augmented Dickey-Fuller Test}

Following the pioneering work by Dickey and Fuller (1979), many studies have employed this tool in empirical macroeconomics after it was popularised by Nelson and Plosser (1982). The standard ADF test is specified as:

$$
\Delta \mathrm{Y}_{\mathrm{t}}=\alpha_{0}+\alpha_{1} \mathrm{t}_{1}+\delta \mathrm{Y}_{\mathrm{t}-1}+\sum_{\mathrm{j}=1}^{\mathrm{L}} \beta_{i} \Delta \mathrm{Y}_{\mathrm{t}-1}+\epsilon_{\mathrm{t}}
$$

Where $\alpha_{0}$ is the constant, $\alpha_{1}$ is the coefficient on the trend term $t, \Delta \mathrm{Y}_{\mathrm{t}-1}$ is the first difference operator to control for serial correlation in the error term, and from the estimation of $\delta$, the 'tau' statistic is obtained and compared to relevant critical values. The null hypothesis is that $\delta$ is zero, i.e. there is a unit root. We reject this hypothesis when the computed statistic is more than the conventional critical values. The assumption regarding the validity of the original Dickey-Fuller test is that the residuals in the regression are not serially correlated. If they are, the aim of the ADF is to add lags to the dependent variable in the above equation until the serial correlation is overcome. 


\subsection{Phillips and Perron Test}

To correct for the possible serial correlation and heteroscedasticity in the residuals of the Dickey-Fuller test, Phillips and Peron (1998) propose an alternative unit root test. These authors use the Newey-West (Newey \& West, 1987) heteroscedasticity and autocorrelation consistent covariance matrix estimator, a non-parametric correction of the Dickey-Fuller test in which allowance is made for possible heteroscedasticity and serial correlation in the residuals. The asymptotic distribution and the critical values for the PP test statistic are the same as in the ADF test. The PP test has a null hypothesis that the series is I(1). However, the PP test has been shown to exhibit an inferior small sample performance relative to the ADF test, and therefore should be used only as a complement to other approaches (see, for example, Schwert, 1989; Campbell \& Perron, 1991; Agiakloglou \& Newbold, 1992; DeJong et al., 1992; and Liu \& Praschnik, 1993).

The test equation is specified as:

$$
\Delta \mathrm{Y}_{\mathrm{t}}=\beta_{0}+\beta_{1} \mathrm{t}+\rho \mathrm{Y}_{\mathrm{t}-1}+\epsilon_{\mathrm{t}}
$$

where $\beta_{0}$ is the constant, $\beta_{1}$ is the coefficient on the trend term $t$, and the 'tau' statistic is obtained from the estimation of $\boldsymbol{\rho}$ and compared to relevant critical values. The null hypothesis is that $\boldsymbol{\rho}$ is zero, i.e. there is a unit root.

\subsection{Predictability of Tax Rate Changes}

Another predictor for the tax smoothing hypothesis to be valid is that tax rate $\tau_{t}$ is unpredictable. In other words, changes in the tax rate $\tau_{t}$ cannot be explained by its own lagged values (univariate regression) or by the lagged values of any other variable in the model. As in the empirical literature, I check for the unpredictability of tax rate by it past values and or by past values of government spending rate $g_{t}$ and real output growth rate $\theta_{t}$ (as a proxy for productivity). Government expenditure and productivity are key determinant variables that influence the tax rate. I can also predict changes in government spending rate $\Delta g_{t}$ and changes in output $\Delta y_{t}$ in the VAR model.

\subsection{Univariate Autoregression}

I start with the tests for whether changes in the tax $\Delta \tau_{t}$, are predictable by its own lagged values by estimating the following autoregression (AR) model:

$$
\Delta \tau_{t}=\beta_{0}+\sum_{\mathrm{j}=1}^{\mathrm{k}} \beta_{j} \Delta \tau_{t-1}+\epsilon_{\mathrm{t}}
$$

Based on the results from equation (22), I employ the $\mathrm{F}$ test under the null hypothesis that $\beta_{1}=\beta_{2}=\cdots \beta_{k}=0$. This means that $\Delta \tau_{t}$ is unpredictable by its own lagged values. I reject the null hypothesis if the F-statistic is less than the critical values and conclude that changes in the tax rate are not influenced by its own lagged value. Thus, the tax rate is unpredictable.

\subsection{Vector Autoregression}

Further, I will test whether changes in the tax rate $\tau_{t}$ can be explained not only by its own lagged values, but by lagged values of changes in government spending rate and output growth rate. As argued by Barro (1981), tests for the unpredictability of changes in tax rate are most thought-provoking in situations where some future changes in relevant variables are predictable. I perform a VAR and check for the predictability of all the variables in the tri-variate VAR by employing the F-test and block exogeneity Wald test.

Consider a VAR model with lag order $\boldsymbol{\rho}$ as follows:

$$
\mathrm{Z}_{\mathrm{t}}=\alpha+\phi_{1} z_{t-1}+\phi_{2} z_{t-2}+\cdots \phi_{p} z_{t-p}+\epsilon_{\mathrm{t}}
$$

where $Z_{\mathrm{t}}=\left[\Delta \tau_{t}, \Delta g_{t}, \Delta y_{t}\right]^{\prime}$ is a vector of endogenous variables in the system, $\boldsymbol{\alpha}$ is a vector of constants, $\phi_{t}$ $(\mathrm{i}=1,2 \ldots, \mathrm{p})$ are $\mathrm{k}$-dimensional coefficient matrices and $\epsilon_{\mathrm{t}}$, is the $\mathrm{k}$ - dimensional vector of residuals.

Assuming a lag length of 2 , the VAR model in equation 23 can be written as:

$$
\left[\begin{array}{l}
\Delta \tau_{t} \\
\Delta g_{t} \\
\Delta y_{t}
\end{array}\right]=\left[\begin{array}{l}
\alpha_{10} \\
\alpha_{20} \\
\alpha_{30}
\end{array}\right]+\left[\begin{array}{lll}
\beta_{11} & \beta_{12} & \beta_{13} \\
\beta_{21} & \beta_{22} & \beta_{23} \\
\beta_{31} & \beta_{32} & \beta_{33}
\end{array}\right]\left[\begin{array}{l}
\Delta \tau_{t-1} \\
\Delta g_{t-1} \\
\Delta y_{t-1}
\end{array}\right]+\left[\begin{array}{lll}
c_{11} & c_{12} & c_{13} \\
c_{21} & c_{22} & c_{23} \\
c_{31} & c_{32} & c_{33}
\end{array}\right]\left[\begin{array}{l}
\Delta \tau_{t-2} \\
\Delta g_{t-2} \\
\Delta y_{t-2}
\end{array}\right]+\left[\begin{array}{l}
\varepsilon_{1} \\
\varepsilon_{2} \\
\varepsilon_{3}
\end{array}\right]
$$

The tax rate changes, $\Delta \tau_{t}$ equation can be written as:

$$
\Delta \tau_{t}=\alpha_{10}+\alpha_{1} \Delta \tau_{t-1}+\alpha_{2} \Delta \tau_{t-2}+\beta_{1} \Delta g_{t-1}+\beta_{2} \Delta g_{t-2}+\varphi_{1} \Delta y_{t-1}+\varphi_{2} \Delta y_{t-2}+\epsilon_{\mathrm{t}}
$$


For simplicity, the coefficients of lags of $\Delta \tau_{t}, \Delta g_{t}$, and $\Delta y_{t}$ have been represented as $\boldsymbol{\alpha}, \boldsymbol{\beta}$ and $\boldsymbol{\varphi}$, respectively.

After estimating the VAR model, I apply the F-test and block exogeneity Wald test to examine the predictability of the variables in the system. The F-test, otherwise known as the joint significance test, is used to test the null hypothesis that in a VAR model, the lagged explanatory variables have no significant influence on the dependent variable, meaning that all the coefficients are instantaneously zero (Greene, 2011; Wooldridge, 2008).

Consider the following tax rate changes $\Delta \tau_{t}$, equation with lag order $\boldsymbol{\rho}$ :

$$
\Delta \tau_{t}=\delta+\sum_{j=1}^{\rho} \alpha_{j} \Delta \tau_{t-j}+\sum_{\mathrm{j}=1}^{\rho} \beta_{j} \Delta g_{t-j}+\sum_{\mathrm{j}=1}^{\rho} \varphi_{j} \Delta y_{t-j}+\epsilon_{\mathrm{t}}
$$

The null hypothesis to be tested is:

$$
H_{0}: \sum_{\mathrm{j}=1}^{\rho} \alpha_{j}=\sum_{\mathrm{j}=1}^{\rho} \beta_{j}=\sum_{\mathrm{j}=1}^{\rho} \varphi_{j}=0
$$

If I fail to reject the null hypothesis, I must conclude there is no evidence that the lagged explanatory variables have significant influence on $\Delta \tau_{t}$ which means that tax rate change is unpredictable.

Additionally, the block exogeneity Wald test is employed with the aim of ascertaining whether each block of lagged variables in each equation in the VAR model can, either individually or jointly, significantly influence each of the dependent variables. To determine this, I restrict all coefficients in each block of lagged variables to zero. For example, the null hypothesis for individual block exogeneity test in $\Delta \tau_{t}$ equation can be written as:

$$
H_{0}: \sum_{\mathrm{j}=1}^{\rho} \beta_{j}=0 \text { or } \sum_{\mathrm{j}=1}^{\rho} \varphi_{j}=0
$$

The block coefficients of lagged $\Delta g_{t}$ and the block coefficients of lagged $\Delta y_{t}$ are respectively:

$$
\sum_{j=1}^{\rho} \beta_{j} \text { and } \sum_{j=1}^{\rho} \varphi_{j}
$$

Meanwhile, the joint block exogeneity test is expressed as:

$$
H_{0}: \sum_{\mathrm{j}=1}^{\rho} \beta_{j}=\sum_{\mathrm{j}=1}^{\rho} \varphi_{j}=0
$$

I use the Wald test of coefficient restriction to test the joint significance of each block of the lagged endogenous variable in each equation in the VAR system, and similarly for the joint significance of all blocks of lagged endogenous variables in each equation of the model. The Wald test, which is based on the likelihood test statistic, is:

$$
(T-c)\left(\log \left|\sum_{r}\right|-\log \left|\sum_{u}\right|\right)
$$

where $\mathrm{T}$ is the number of observations and $\mathrm{c}$ is the number of parameters estimated in each equation of the unrestricted VAR model. $\sum_{r}$ and $\sum_{u}$ are the variance/covariance matrices of the restricted and unrestricted VAR system.

\section{Empirical Results}

This section presents the empirical results regarding whether the tax smoothing hypothesis holds in Sierra Leone. Both the random walk and predictability tests are applied, and the results are presented as follows.

I start by examining the existence of unit root in tax rate, a necessary condition for the tax smoothing hypothesis. To do so, I employ a battery of unit root tests. The results are presented in Table 1.

The unit root tests are performed both with and without the trend term included. The null hypothesis of the unit root in tax rate $\tau_{t}$ is not rejected at 5\% significance level for the ADF and PP tests. For the ADF test, the test statistics with and without trend are -3.402 and -2.973 , respectively, which are less than the 5\% critical values of -3.640 and -2.946 in absolute terms. With regards to the PP test, the test statistics with and without trend are 
-3.587 and -2.817 , respectively, which are less than the 5\% critical values of -3.640 and -2.946 in absolute terms. The results indicate that the null hypothesis of unit root in the tax rate cannot be rejected at the $5 \%$ conventional level. As in Barro (1986), Trehan and Walsh (1988), Ashworth and Evans (1998) etc, these findings support the random walk behaviour of the tax rate which is consistent with tax smoothing theory.

Table 1. Results of Unit Root Tests for Tax Rate

\begin{tabular}{lllll}
\hline & \multicolumn{2}{c}{ ADF } & PP \\
\cline { 2 - 5 } & With Trend & No Trend & With Trend & No Trend \\
\hline Test Stats. & -3.402 & -2.793 & -3.587 & -2.817 \\
Critical Values & & & & -3.627 \\
$1 \%$ & -4.235 & -3.627 & -4.235 & -2.946 \\
$5 \%$ & -3.640 & -2.946 & -3.640 & $-2.612^{*}$ \\
\hline
\end{tabular}

ADF -Lags selections were based on the Schwarz Information Criterion, where * represents a statistical significance level of $10 \%$.

PP Lag selections were based on the Newey-West Bandwidth test using the Bartlett Kernel Criterion, where * represent statistical significance levels of $10 \%$.

In summary, based on results obtained from the various unit root tests, I find evidence that tax rate is non-stationary. The tax rate thus follows a random walk - a result that is consistent with the tax smoothing hypothesis.

Another requirement for tax smoothing to hold is that tax rate should be unpredictable, i.e. the tax rate should not be predicted by its own lagged values. On this note, I examines whether tax rate changes are predictable by either its own lag values. Based on the lag selection criteria, the AIC suggest that the model should be estimated with two lags. However, to have richer information on the predictability of changes in the tax rate, the model is estimated with the lag order of 1,2,3 and 4. The results are presented in Table 2.

Table 2. Univariate Autoregression Results

\begin{tabular}{|c|c|c|c|c|}
\hline & Number of & Lags & & \\
\hline Coefficients & Lag 4 & Lag 3 & Lag 2 & Lag 1 \\
\hline \multirow[t]{2}{*}{$\alpha_{0}$} & 0.078 & 0.080 & 0.007 & -0.133 \\
\hline & $(0.268)$ & $(0.254)$ & $(0.021)$ & $(-0.392)$ \\
\hline \multirow[t]{2}{*}{$\alpha_{1}$} & -0.183 & -0.104 & -0.010 & -0.044 \\
\hline & $(-0.976)$ & $(-0.609)$ & $(-0.056)$ & $(-0.245)$ \\
\hline \multirow[t]{2}{*}{$\alpha_{2}$} & 0.101 & 0.116 & 0.102 & \\
\hline & $(0.581)$ & $(0.733)$ & $(0.614)$ & \\
\hline \multirow[t]{2}{*}{$\alpha_{3}$} & -0.212 & -0.220 & & \\
\hline & $(-1.320)$ & $(-1.388)$ & & \\
\hline \multirow[t]{2}{*}{$\alpha_{4}$} & -0.189 & & & \\
\hline & $(-1.146)$ & & & \\
\hline F-stat & 1.059 & 1.048 & 0.192 & 0.064 \\
\hline Prob. (F-stat) & $(0.396)$ & $(0.386)$ & $(0.827)$ & $(0.802)$ \\
\hline
\end{tabular}

Note. Numbers in parentheses are t-statistics.

Table 2. shows the coefficient for tax rate at lag 1 is -0.044 . The F-stat is 0.064 , with a corresponding probability value of 0.802 . One lag value of tax rate cannot predict changes in the tax rate, as the probability value is insignificant. At lag 2, the coefficient for tax rate is 0.102 . The F-stat is 0.192 , with a corresponding probability value of 0.827 . At lag 2, the value of tax rate cannot predict changes in tax rate, as the probability value is insignificant. For lag 3, the coefficient for tax rate is -0.220 . The F-stat is 1.048 , with a corresponding probability value of 0.386 . At lag 3, the value of tax rate cannot predict changes in tax rate, as the probability value is insignificant. Finally, at lag 4 , the coefficient for tax rate is -0.189 . The F-stat is 1.059 , with a corresponding probability value of 0.396 . At lag 4 , the value of tax rate cannot predict changes in the tax rate as the probability value is insignificant. The F-tests obtained from the different lag lengths in the univariate autoregression are not significant at the 5\% level. These results imply that the null hypothesis of zero coefficients for the lagged values of changes in the tax rate cannot be rejected. Therefore, I conclude that during the sample period under investigation, tax rate changes cannot be predicted by its own lagged values, providing evidence that the tax smoothing theory holds in Sierra Leone. Similar conclusions were reached by Kurniawan (2011) for Indonesia, 
and by Karakas, Taner and Yanikkaya (2014) for Turkey.

I proceed further to test whether tax rate changes $\Delta \boldsymbol{\tau}_{t}$, can be predicted not only by its own lagged values, but also by the lagged values of changes in government spending rate $\Delta \boldsymbol{g}_{\boldsymbol{t}}$ and GDP growth rate $\Delta \boldsymbol{y}_{\boldsymbol{t}}$. I proceed to show the estimates from the VAR results for tax rate, government spending rate and growth rate of output. However, for consistency with the autoregression results of tax rate changes and to have more insight into and richer results regarding the predictability of the variables, I present the estimates from lag 1 to 4 . The result from the VAR with four lags is presented in Table 3.

Table 3. VAR results

\begin{tabular}{llllll}
\hline Dependent Variables & Lag order in VAR & $\boldsymbol{R}^{\mathbf{2}}$ & F-stat & Prob. (F-stat) & DW \\
\hline$\Delta \boldsymbol{\tau}_{\boldsymbol{t}}$ & 1 & 0.062 & 0.680 & 0.571 & 1.787 \\
& 2 & 0.092 & 0.456 & 0.834 & 2.125 \\
& 3 & 0.227 & 0.751 & 0.660 & 2.105 \\
$\Delta \boldsymbol{g}_{\boldsymbol{t}}$ & 4 & 0.250 & 0.528 & 0.871 & 2.079 \\
& 1 & 0.085 & 0.962 & 0.423 & 2.015 \\
& 2 & 0.256 & 1.551 & 0.199 & 2.244 \\
$\Delta \boldsymbol{y}_{\boldsymbol{t}}$ & 3 & 0.461 & $2.189 *$ & 0.063 & 1.901 \\
& 4 & 0.494 & 1.546 & 0.190 & 1.795 \\
& 1 & 0.015 & 0.512 & 0.928 & 1.997 \\
\end{tabular}

Note. * indicate significance at the $10 \%$ level.

The VAR results above show that for the tax rate changes $\Delta \boldsymbol{\tau}_{\boldsymbol{t}}$ equation, that is where $\Delta \boldsymbol{\tau}_{\boldsymbol{t}}$ is the dependent variable, I cannot reject the null hypothesis of zero coefficient restrictions for all lagged variables in the equation. The F-statistics of $0.680,0.456,0,751$ and 0.528 for the VAR, with lag orders 1, 2, 3 and 4, respectively, are not significant at any conventional significance level. I conclude that tax rate changes are not predictable by all the lagged variables during the period under review.

When change in government spending $\Delta \boldsymbol{g}_{\boldsymbol{t}}$ is the dependent variable, the result shows that changes in government spending can be predicted by its own lag, but only in the third year. The F-statistics of 0.962 and 1.551 for lag order 1 and 2, respectively, are not significant. However, the F-statistic of 2.189 is significant at the $10 \%$ level. For the growth rate of real GDP equation, the results indicate that for a period up to four lags, real GDP growth rate is not predictable by its own lagged values. The F-statistics of 0.512, 0.709, 0.812 and 1.227 for lag orders 1,2,3, and 4 respectively are all insignificant at each of the conventional levels.

In Table 4, I present the block exogeneity Wald test of coefficient restriction based on the VAR, with two lags chosen by the AIC to be optimal. The results are presented in three categories: the first part shows whether I can exclude, separately or jointly, the blocks of lags of changes in government spending rate $\Delta \boldsymbol{g}_{\boldsymbol{t}}$ and changes in growth rate of real GDP $\boldsymbol{y}_{\boldsymbol{t}}$ from changes in the tax rate $\Delta \boldsymbol{\tau}_{\boldsymbol{t}}$ equation. The next rows test for the same hypotheses.

Table 4. Block Exogeneity Wald Test Results

\begin{tabular}{lllll}
\hline Dependent Variable & Excluded Variables & Chi-sq & df & P-value \\
\hline$\Delta \boldsymbol{\tau}_{\boldsymbol{t}}$ & $\Delta g_{t}$ & 1.090 & 2 & 0.580 \\
& $\Delta y_{t}$ & 1.617 & 2 & 0.445 \\
& All & 2.374 & 4 & 0.667 \\
$\boldsymbol{g}_{\boldsymbol{t}}$ & $\Delta \tau_{t}$ & $5.586^{*}$ & 2 & 0.061 \\
& $\Delta y_{t}$ & 1.797 & 2 & 0.407 \\
& All & 7.137 & 4 & 0.129 \\
$\boldsymbol{y}_{\boldsymbol{t}}$ & $\Delta \tau_{t}$ & 0.435 & 2 & 0.805 \\
& $\triangle g_{t}$ & 2.414 & 2 & 0.299 \\
\hline
\end{tabular}

Note. * indicate significance at the $10 \%$ level. The term 'All' refers to the exclusion of lags of all variables other than the lags of the dependent variables. 
The results in Table 4. show that when tax rate changes $\Delta \boldsymbol{\tau}_{\boldsymbol{t}}$ is the dependent variable, the null hypothesis of excluding lags of changes in government spending rate $\Delta \boldsymbol{g}_{\boldsymbol{t}}$ and changes in growth rate of real GDP $\Delta \boldsymbol{y}_{\boldsymbol{t}}$ cannot be separately or jointly rejected. The chi-square values of 1.090 (with p-value $=0.580$ ) and 1.617 (with p-value $=0.445)$ for $\Delta \boldsymbol{g}_{\boldsymbol{t}}$ and $\Delta \boldsymbol{y}_{\boldsymbol{t}}$ are insignificant, implying that the block of lags of the two variables can be excluded from the tax rate changes $\Delta \boldsymbol{\tau}_{\boldsymbol{t}}$ equation separately. Moreover, the chi-square value of 2.374 (with $\mathrm{p}$-value $=0.667$ ) for the exclusion of all variables is also insignificant. This implies that tax rate changes are unpredictable by the arrival of new information, which is consistent with tax smoothing theory. The findings result is in line with Kurniawan (2011) and Karakas, Taner and Yanikkaya (2014), among other studies.

The block lags of changes in government spending rate $\Delta \boldsymbol{g}_{\boldsymbol{t}}$ and changes in growth rate of real GDP $\Delta \boldsymbol{y}_{\boldsymbol{t}}$ can thus be jointly excluded from changes in tax rate $\Delta \boldsymbol{\tau}_{\boldsymbol{t}}$ equation. Based on these results, I can therefore conclude that tax rate changes $\Delta \boldsymbol{\tau}_{\boldsymbol{t}}$ are not predicted by changes in government spending $\Delta \boldsymbol{g}_{\boldsymbol{t}}$ and changes in growth rate of real GDP $\Delta \boldsymbol{y}_{\boldsymbol{t}}$, either individually or jointly. When changes in government spending rate $\Delta \boldsymbol{g}_{\boldsymbol{t}}$ is the dependent variable, the results show that the blocks of lags of tax rate changes $\Delta \boldsymbol{\tau}_{\boldsymbol{t}}$ and growth rate of real GDP $\Delta \boldsymbol{y}_{\boldsymbol{t}}$ can jointly be excluded from changes in the government spending rate $\Delta \boldsymbol{g}_{\boldsymbol{t}}$ equation. The chi-square value of 7.137 (with p-value $=0.129$ ) is insignificant at $5 \%$ or lower. Therefore, $\Delta \boldsymbol{g}_{\boldsymbol{t}}$ cannot be jointly predicted by $\Delta \boldsymbol{\tau}_{\boldsymbol{t}}$ and $\Delta \boldsymbol{y}_{\boldsymbol{t}}$. However, separately, the result shows that the blocks of lags of tax rate changes $\Delta \boldsymbol{\tau}_{\boldsymbol{t}}$ have significant power in predicting $\Delta \boldsymbol{g}_{t}$. The chi-square of 5.586 (with p-value $=0.061$ ) is significant at the $10 \%$ level.

Finally, the results show that when changes in GDP growth rate $\Delta \boldsymbol{y}_{\boldsymbol{t}}$ is the dependent variable, the null hypothesis of excluding lags of changes in government spending rate $\Delta \boldsymbol{g}_{\boldsymbol{t}}$ and changes in tax rate $\Delta \boldsymbol{\tau}_{\boldsymbol{t}}$ cannot be separately or jointly rejected. The chi-square value of 0.435 (with p-value $=0.805)$ and 2.414 (with p-value $=$ 0.299) for $\Delta \boldsymbol{\tau}_{\boldsymbol{t}}$ and $\Delta \boldsymbol{g}_{\boldsymbol{t}}$ are insignificant, which implies that the block of lags of the two variables can be excluded from changes in real GDP growth $\Delta \boldsymbol{y}_{\boldsymbol{t}}$ equation separately. Moreover, the chi-square value of 4.046 (with p-value $=0.399$ ) for the exclusion of all variables is also insignificant. Thus, the block lags of changes in government spending rate $\Delta \boldsymbol{g}_{\boldsymbol{t}}$ and changes in tax rate $\Delta \boldsymbol{\tau}_{\boldsymbol{t}}$ can be jointly excluded from the changes growth rate $\Delta \boldsymbol{y}_{\boldsymbol{t}}$ equation.

\section{Conclusion}

In this paper, I empirically investigated whether the tax policies that has been implemented under the review period are consistent with optimal tax policy. To achieve this aim, three different empirical approaches were performed. Firstly,the unit root tests to examine the random walk property of the tax rate. The null hypothesis of non-stationarity of tax rate could not be rejected, which implies the tax rate follows random walk and hence is consistent with optimal tax policy. Second, I examined whether changes in tax rate is predictable by regressing changes in tax rate by its own lagged values. The result shows that tax rate is unpredictable, as changes in tax cannot be determined by its lagged values. This finding also supports the existence of the tax smoothing hypothesis hence optimal tax policy. Finally, a VAR model was employed to examine whether tax rate can be predicted by its own lagged values together with changes in the government spending rate and the growth rate of real GDP. The results indicate that all the variables employed were found not be significant is predicating the tax rate. Overall, the empirical estimations supports the existence of tax smoothing over the sample period and that the budget inbalance is consistent with optimal tax policy.

\section{References}

Abuselidze, G. (2012). The influence of optimal tax burden on economic activity and production capacity. Intelektine ekonomika, 6(4), 493-503.

Agiakloglou, C., \& Newbold, P. (1992). Empirical evidence on Dickey-Fuller-type tests. Journal of Time Series Analysis, 13(6), 471-483. https://doi.org/10.1111/j.1467-9892.1992.tb00121.x

Ashworth, J., \& Evans, L. (1998). Seigniorage and tax smoothing in developing countries. Journal of Economic Studies. https://doi.org/10.1108/01443589810233865

Barro, R. J. (1979). On the determination of the public debt. Journal of political Economy, 87(5, Part 1), 940-971. https://doi.org/10.1086/260807

Barro, R. J. (1981). On the predictability of tax-rate changes (No. w0636). National Bureau of Economic Research. https://doi.org/10.3386/w0636

Belguith, S. O., Gabsi, F. B., \& Mtibaa, A. (2018). Tax smoothing hypothesis: The Tunisian case. Theoretical \& Applied Economics, 25(4). 
Campbell, J. Y. (1986). Does saving anticipate declining labor income? An alternative test of the permanent income hypothesis. https://doi.org/10.3386/w1805

Campbell, J. Y., \& Perron, P. (1991). Pitfalls and opportunities: what macroeconomists should know about unit roots. NBER Macroeconomics Annual, 6, 141-201. https://doi.org/10.1086/654163

Campbell, J. Y., \& Shiller, R. J. (1987). Cointegration and tests of present value models. Journal of Political Economy, 95(5), 1062-1088. https://doi.org/10.1086/261502

Cashin, M. P., Sahay, M. R., \& Olekalns, N. (1998). Tax Smoothing in a financially repressed economy: Evidence from India. International Monetary Fund. https://doi.org/10.2139/ssrn.882668

Cashin, P. A., Ul Haque, N., \& Olekalns, N. (1999). Spend now, pay later? Tax smoothing and fiscal sustainability in South Asia. https://doi.org/10.2139/ssrn.880590

Cashin, P., Haque, N. U., \& Olekalns, N. (2003). Tax smoothing, tax tilting and fiscal sustainability in Pakistan. Economic Modelling, 20(1), 47-67. https://doi.org/10.1016/S0264-9993(01)00085-2

Crosby, M., \& Olekalns, N. (1998). Some long run evidence on tax smoothing. Department of Economics Research Paper 609, University of Melbourne.

DeJong, D. N., Nankervis, J. C., Savin, N. E., \& Whiteman, C. H. (1992). Integration versus trend stationary in time series. Econometrica: Journal of the Econometric Society, 423-433. https://doi.org/10.2307/2951602

Dickey, D. A., \& Fuller, W. A. (1979). Distribution of the estimators for autoregressive time series with a unit root. Journal of the American statistical association, 74(366a), 427-431. https://doi.org/10.1080/01621459.1979.10482531

Ghosh, A. R. (1995). Intertemporal tax-smoothing and the government budget surplus: Canada and the United States. Journal of Money, Credit and Banking, 27(4), 1033-1045. https://doi.org/10.2307/2077787

Greene, W. H. (2011). Econometric Analysis (7th ed.). Prentice Hall.

Hall, R. E. (1978). Stochastic implications of the life cycle-permanent income hypothesis: Theory and evidence. Journal of political economy, 86(6), 971-987. https://doi.org/10.1086/260724

Horrigan, B. R. (1986). The Determinants of the Public Debt in the United States, 1953-1978. Economic Inquiry, 24(1), 11-23. https://doi.org/10.1111/j.1465-7295.1986.tb01794.x

Huang, C. H., \& Lin, K. S. (1993). Deficits, government expenditures, and tax smoothing in the United States: 1929-1988. Journal of Monetary Economics, 31(3), 317-339. https://doi.org/10.1016/0304-3932(93)90051-

Jayawickrama, A., \& Abeysinghe, T. (2013). The experience of some OECD economies on tax smoothing. Applied Economics, 45(16), 2305-2313. https://doi.org/10.1080/00036846.2012.663472

Karakas, M., Taner, T., \& Yanikkaya, H. (2014). A brief analysis of the tax smoothing hypothesis in Turkey. Transylvanian Review of Administrative Sciences, 10(42), 78-93.

Kingston, G. (1991). Should marginal tax rates be equalized through time? The Quarterly Journal of Economics, 106(3), 911-924. https://doi.org/10.2307/2937933

Kingston, G. H. (1984). Efficient timing of income taxes. Journal of Public Economics, 24(2), 271-280. https://doi.org/10.1016/0047-2727(84)90030-6

Kingston, G. H., \& Layton, A. P. (1986). The Tax Smoothing Hypothesis: Some Australian Empirical Results. Australian Economic Papers, 25(47), 247-251. https://doi.org/10.1111/j.1467-8454.1986.tb00798.x

Krumplyte, J. (2008). The concept of shadow economy and causal analysis. Economics and Management: Current Issues and Perspectives, 4(13), 238-250.

Kurniawan, R. (2011). Tax smoothing: Tests on Indonesian data. International Journal of Economics and Finance Studies, 3(1), 187-197.

Liu, P. C., \& Praschnik, J. (1993). The size of the nonstationary component and its effect on tests for unit roots. Statistical Papers, 34(1), 83-88. https://doi.org/10.1007/BF02925529

Nelson, C. R., \& Plosser, C. R. (1982). Trends and random walks in macroeconmic time series: Some evidence and implications. Journal of monetary economics, 10(2), 139-162. https://doi.org/10.1016/0304-3932(82)90012-5

Newey, W. K., \& West, K. D. (1987). Hypothesis testing with efficient method of moments estimation. International Economic Review, 777-787. https://doi.org/10.2307/2526578 
Olekalns, N. (1997). Australian evidence on tax smoothing and the optimal budget surplus. Economic Record, 73(222), 248-257. https://doi.org/10.1111/j.1475-4932.1997.tb00998.x

Pasten, R., \& Cover, J. P. (2011). Does the Chilean government smooth taxes? A tax-smoothing model with revenue collection from a natural resource. Applied Economics Letters, 18(5), 421-425. https://doi.org/10.1080/13504851003705274

Phillips, P. C., \& Perron, P. (1988). Testing for a unit root in time series regression. Biometrika, 75(2), 335-346. https://doi.org/10.1093/biomet/75.2.335

Piketty, T., Saez, E., \& Stantcheva, S. (2014). Optimal taxation of top labor incomes: A tale of three elasticities. American economic journal: economic policy, 6(1), 230-71. https://doi.org/10.1257/pol.6.1.230

Rocha, F. (2001). Is there any rationale to the Brazilian fiscal policy?. Revista Brasileira de Economia, 55, 315-331. https://doi.org/10.1590/S0034-71402001000300001

Sahasakul, C. (1986). The US evidence on optimal taxation over time. Journal of Monetary Economics, 18(3), 251-275. https://doi.org/10.1016/0304-3932(86)90039-5

Schwert, G. W. (2002). Tests for unit roots: A Monte Carlo investigation. Journal of Business \& Economic Statistics, 20(1), 5-17. https://doi.org/10.1198/073500102753410354

Serletis, A., \& Schorn, R. G. (1999). International evidence on the tax-and revenue-smoothing hypotheses. Oxford Economic Papers, 51(2), 387-396. https://doi.org/10.1093/oep/51.2.387

Sinevičienè, L. (2016). Tax burden and economic development: the case of the European Union Countries. Entrepreneurship, Business and Economics, 2, 283-298. Springer, Cham. https://doi.org/10.1007/978-3-319-27573-4_19

Strazicich, M. C. (1996). Are state and provincial governments tax smoothing? Evidence from panel data. Southern Economic Journal, 979-988. https://doi.org/10.2307/1060942

Strazicich, M. C. (1997). Does tax smoothing differ by the level of government? Time series evidence from Canada and the United States. Journal of Macroeconomics, 19(2), 305-326. https://doi.org/10.1016/S0164-0704(97)00017-7

Strazicich, M. C. (2002). International evidence of tax smoothing in a panel of industrial countries. Applied Economics, 34(18), 2325-2331. https://doi.org/10.1080/00036840210143107

Talvi, E., \& Vegh, C. A. (2005). Tax base variability and procyclical fiscal policy in developing countries. Journal of Development Economics, 78(1), 156-190. https://doi.org/10.1016/j.jdeveco.2004.07.002

Trehan, B., \& Walsh, C. E. (1990). Seigniorage and tax smoothing in the United States 1914-1986. Journal of Monetary Economics, 25(1), 97-112. https://doi.org/10.1016/0304-3932(90)90047-8

Wooldridge, J. M. (2015). Introductory econometrics: A modern approach. Cengage learning.

\section{Copyrights}

Copyright for this article is retained by the author(s), with first publication rights granted to the journal.

This is an open-access article distributed under the terms and conditions of the Creative Commons Attribution license (http://creativecommons.org/licenses/by/4.0/). 